\title{
Estimation of plant sterol and cholesterol intake in Finland: quality of new values and their effect on intake
}

\author{
L. M. Valsta ${ }^{1}$, A. Lemström ${ }^{2} \dagger$, M.-L. Ovaskainen ${ }^{1}$, A.-M. Lampi ${ }^{2}$, J. Toivo $^{2} \ddagger$, T. Korhonen ${ }^{1,2}$ \\ and V. Piironen ${ }^{2}$ \\ ${ }^{1}$ Department of Epidemiology and Health Promotion, Nutrition Unit, The National Public Health Institute, \\ Mannerheimintie 166, FIN-00300 Helsinki, Finland \\ ${ }^{2}$ The Department of Applied Chemistry and Microbiology at the University of Helsinki, P. O. B. 27, \\ FIN-00014 University of Helsinki, Finland
}

(Received 28 August 2003 - Revised 19 May 2004 - Accepted 14 June 2004)

\begin{abstract}
The Finnish national food composition database Fineli ${ }^{\circledR}$ was updated with recent analytical values for plant sterols (PS) (sitosterol, campesterol, stigmasterol, avenasterol, brassicasterols and stanols) and cholesterol. The quality of the new analytical data was assessed. The aims of the present study were: (1) to compare the effect of old and new database values on PS and cholesterol intakes based on average per capita food consumption data; (2) to estimate the current intake and major sources of these compounds in various population groups according to the national FINDIET 1997 survey data. The intake of total PS was $305 \mathrm{mg} / \mathrm{d}$ for men and $237 \mathrm{mg} / \mathrm{d}$ for women. The respective intakes for cholesterol were $284 \mathrm{mg} / \mathrm{d}$ and $201 \mathrm{mg} / \mathrm{d}$. Women had a higher density of PS in their diets than men, whereas the cholesterol density in the diets did not differ between genders. Cereals, margarine, vegetables and vegetable oils were the main food sources of PS. Meat, meat products and eggs were the main sources of cholesterol. A $9 \%$ greater PS intake estimate was obtained with the new PS database compared with the old PS database, probably due to minor methodological differences between the new and old analyses. Notable changes in analytical methods suggest a lower value $(-19 \%)$ for cholesterol intake calculated from the new database compared with the old one. We conclude that researchers can have confidence in the new values for PS and cholesterol, because systematic evaluation of the new analytical values showed them to be of high quality.
\end{abstract}

Cholesterol: Plant sterols: Food composition database: Dietary intake

The associations of high dietary plant sterol (PS) and cholesterol (Chol) intakes with the risk factors or outcome of chronic diseases have fascinated researchers for many years. These sterol compounds affect, for instance, one of the main risk factors of CHD, namely serum LDL-Chol levels. It has been shown that the intake of recently launched margarines containing PS or PS esters lowers the total concentration of serum Chol on average by $10-15 \%$ and the total concentration of LDL-Chol by up to $20 \%$ (Miettinen \& Gylling, 1999; Moghadasian, 1999; Moreau et al. 2002). The atherogenity of Chol-rich foods can be attributed to the fact that these foods are usually rich in saturated fatty acids, whereas the atherogenity of Chol in itself is reasonably low (McNamara, 2000). However, food Chol content per se is crucial for certain population groups that are genetically sensitive to dietary Chol (Kesäniemi et al. 1987). It has also been suggested, based mainly on animal and in vitro studies, that PS have protective effects against cancer (Awad \& Fink, 2000); however, with regard to colon cancer, for example, preventive effects (Nair et al. 1984), but also no effects (Normén et al. 2001), have been reported. The possible increase in cancer risk due to high-Chol diets seems to be restricted to lung and pancreatic cancers (Anonymous, 1997).

To gain a better understanding of the associations between PS and Chol intake, their dietary ratios and their effect on human health, epidemiologists require up-todate dietary intake data (Piironen et al. 2000a). For such information to be available, carefully constructed food composition databases covering the compounds of interest are needed. It has been proposed that qualitative evaluation of the analytical values in a database should include the documentation and execution of the sampling plan, the number of samples, sample handling, analytical method, and use of controls and standards (Greenfield \& Southgate, 1992; Mangels \& Holden, 1993; Ovaskainen et al. 1996).

Some recent reports have provided estimates of PS intakes in Europe. The total PS intake in a normal population has

\footnotetext{
Abbreviations: Chol, cholesterol; PS, plant sterol.

* Corresponding author: Dr Liisa Valsta, fax + 3589474485 91, email liisa.valsta@ktl.fi

$\dagger$ Present address: Ministry of Trade and Industry, P. O. B. 32, FIN-00023 Valtioneuvosto, Finland.

$\uparrow$ Present address: National Technology Agency of Finland, TEKES, P. O. B. 69, FIN-00101 Helsinki, Finland.
} 
been reported to vary from $200 \mathrm{mg} / \mathrm{d}$ (Morton et al. 1995) to $350 \mathrm{mg} / \mathrm{d}$ (Schothorst \& Jekel, 1999). Vegetarians are believed to have the highest intakes, due to high consumption of dietary sources of sterols (Piironen et al. 2000a). Estimates of Chol intake in Europe range from about $200 \mathrm{mg} / \mathrm{d}$ per person (Moschandreas \& Kafatos, 1999; Schothorst \& Jekel, 1999) to about $400 \mathrm{mg} / \mathrm{d}$ per person (Hermann-Kunz $\&$ Thamm, 1999). From these results, it can be inferred that the PS:Chol ratio normally lies between 0.5 and 1.0 . There are no official recommendations concerning the PS:Chol ratio of the diet, but it has been stated that a diet containing more PS than Chol, i.e. ratio $>1 \cdot 0$, would be beneficial for health (Pelletier et al. 1995).

When estimating the dietary intake of specific nutrients in a population, researchers have to have sufficient and valid data on the nutrients in foods commonly consumed by that population. A PS database, compiled from different foreign literature sources from 1978 onwards (Heinonen et al. 1997), has been available for dietary studies in Finland since the mid-1990s (Tammi et al. 2001). We revised this database by including recent Finnish analytical data, to facilitate future epidemiological studies. The update was motivated not only by the need for data on the national food supply for national studies, but also by the fact that the chemical methods used for PS analyses have been improved recently (Piironen et al. 2000a; Toivo et al. 2001). As for Chol, data on the Chol content of Finnish food items have been based on analytical values generated in the 1970s, and up to now intake estimates have been derived from these data. Great advances have also been made in the chemical procedures for Chol analysis (Fenton, 1992); therefore it was important to revise the existing Chol database as well.

In the present paper we report the evaluation of the newly compiled PS and Chol databases and present new intake estimates for PS and Chol in different population groups.

\section{Materials and methods}

\section{Food sampling and chemical analytical methods}

For the analyses of PS and Chol in Finnish foods, food samples were collected in a way that approximately represented their quantitative market shares. All sampled food items are commonly consumed in Finland (Salminen, 1997; Piironen et al. 2000a,b, 2002b, 2003). For each food item, ten sub-samples from major food stores in the capital area were collected. Generally, for each food item, a pooled sample of these ten sub-samples was prepared for sterol analysis. Since vegetable oils and margarines are important sources of PS, sampling and analysis of these items was repeated. For other food groups, sampling of selected items was repeated to provide information about variation in sterol contents. Further, the validity of the sampling of animal products was confirmed through individual analysis of ten sub-samples of each class of products (meat, fish, dairy products and eggs). The sampling of one vegetable oil and one margarine was similarly confirmed.

Sample preparation, GC analysis and validation of the procedures, reagents and instruments are described for each food group in detail in the original papers (Toivo et al. 1998, 2000, 2001; Piironen et al. 2002a,b, 2003). Modifications needed in the method when it was used for analyses of different food groups were tested and reported. Briefly, sterol contents were determined using sample preparation methods capable of hydrolysing all bound sterol classes to corresponding non-esterified sterols, which were determined by GC. Thus, the sample preparation procedures for vegetables and cereal products included both acid and alkaline hydrolysis to liberate sterols both from their glycosides and esters. For vegetable oils, margarines and animal products, only alkaline hydrolysis, to liberate sterols from their esters, was needed. All samples were analysed in triplicate.

Acid hydrolysis was carried out with $6 \mathrm{M}-\mathrm{HCl}$ in ethanol at $80-85^{\circ} \mathrm{C}$ for $60 \mathrm{~min}$ (Toivo et al. 2001; Piironen et al. $2002 b, 2003)$. Thereafter, the lipids in cereal product and vegetable samples were extracted with hexane-diethyl ether $(1: 1, v / v)$ solvent mixture and saponified with $\mathrm{KOH}$ at $80-85^{\circ} \mathrm{C}$ for $30 \mathrm{~min}$. The unsaponifiable part was extracted with cyclohexane. The extracts were purified using either $\mathrm{C}_{18}$ or $\mathrm{SiOH}$ cartridge solid-phase extraction. Sterols were silylated with N,O-Bis(trimethylsilyl)trifluoroacetamide-trimethylchlorosilan (99:1, by vol.) in pyridine and determined by GC (Hewlett Packard, Boeblingen, Germany) with on-column injection and flame ionisation detection and an RTX-5w/INTEGRA fused silica capillary column (Restek Corp., Bellefonte, PA, USA). When necessary, GC-MS identification was used. Sterols were quantified using either Chol or later dihydrocholesterol as an internal standard. The internal standard was added at the beginning of the determination. A blank test without any internal standard was run for each material to ascertain that there were no interfering peaks. When Chol was used as an internal standard, trace amounts of Chol found in the samples were taken into account when calculating the results.

Oil and margarine samples were saponified with $\mathrm{KOH}$ for $20 \mathrm{~min}$ at $80^{\circ} \mathrm{C}$ (Toivo et al. 1998). Extracted sterols were purified using $\mathrm{C}_{18}$ cartridges and the silylated sterols were quantified by $\mathrm{GC}$-flame ionisation detector using betulin as an internal standard.

Homogenised animal product samples were mixed with the internal standard (epicholesterol or later dihydrocholesterol) and saponified with $\mathrm{KOH}$ at $85^{\circ} \mathrm{C}$ for 30 or $60 \mathrm{~min}$ depending on the sample (Piironen et al. 2002a). After extracting the unsaponifiable matter with cyclohexane, the sterols were silylated without further purification and analysed by GC as described earlier.

\section{Assessment of quality of compositional data}

The new analytical values were stored in the national food composition database, Fineli ${ }^{\circledR}$. The variables included in the new database were Chol, sitosterol, campesterol, stanols (including sitostanol and campestanol), stigmasterol, avenasterols (including $\Delta 5$ - and $\Delta 7$-avenasterols), brassicasterol and other PS. Altogether, analytical values for PS in ninety-nine food items (mainly vegetable oils and margarines, vegetables, fruits, cereals and cereal products) and values for Chol in 125 food items (dairy products, fish, 
eggs, meat and meat products) were included in the food composition database. More than one-half of the values for Chol stemmed from food items that also contained PS. In all, 3700 new values were stored in the database. Some of the analysed values were used directly for the corresponding food codes in the database, while others provided the basis for derivation of values in analogous products, done for example, by regression models. Another set of analysed values were of Swedish origin; these were taken from Normén et al. (1999). A few values were obtained from manufacturer's information or food composition tables, after thorough evaluation by an expert. About $60 \%$ of the PS values and $63 \%$ of the Chol values in the new database were obtained through recipe calculations.

The method of evaluation of analytical values was adapted from internationally recommended procedures (Greenfield \& Southgate, 1992; Mangels \& Holden, 1993; Table 1). A column for ranking the number of samples was added, since this was considered to be of essential importance to data quality. A new scaling for the sum of quality indices corresponding to the confidence codes was added, in order to describe the quality of new values.

In order to compare intake differences caused by changes in the PS and Chol databases, intake estimates were calculated using both the former and the new PS and Chol databases and the same per capita consumption data, taken from Balance Sheets for Food Commodities 1998 and 1999 (Information Centre of the Ministry of Agriculture and Forestry, 2000).

In this estimation the average per capita consumption of 3 years $(1996,1997,1998)$ was used.

\section{Dietary survey}

Individual food consumption data were obtained from the national FINDIET 1997 study, carried out in a random sample of the adult population (25-64 years old) stratified by 10-year age group and area, in five areas in Finland (FINDIET Study Group, 1998). Dietary data were collected by computerised $24 \mathrm{~h}$ recall $(n$ 2862); from these data the average dietary intakes were calculated. Demographic background data were collected with a structured questionnaire. The Chol and PS densities $(\mathrm{mg} / 1000 \mathrm{~kJ})$ of the diets were then compared across four 10-year age groups and three educational levels. Since users of stanol ester margarine ( $n$ 124) had markedly high intakes of PS, they were excluded from further analyses. Thus, the final sample consisted of 2738 subjects (1292 men and 1446 women). In all, 1374 food codes listed in the food composition database, including various food items and dishes with recipes, were used by the participants in the dietary survey.

\section{Statistical methods}

Statistical analyses were performed using SAS System (version 6.12; SAS Institute Inc., Cary, NC, USA). A mixed model for measurement error (SAS System, procedure MIXED) was applied in testing the differences between different population categories in nutrient intakes on the basis of $24 \mathrm{~h}$ recall. The model uses auxiliary information on $48 \mathrm{~h}$ dietary recall and $3 \mathrm{~d}$ food record data collected in a random sub-sample of subjects from the study population (n 223 and $n 334$ respectively), to minimise the effect of daily variation (Carroll et al. 1995). $P$ values $<0.05$ were considered significant.

Table 1. Criteria for quality indices of analytical data*

\begin{tabular}{|c|c|c|c|c|}
\hline Quality index & $\begin{array}{l}\text { Documentation of } \\
\text { analytical method }\end{array}$ & $\begin{array}{l}\text { Sample handling } \\
\text { and documentation }\end{array}$ & Quality control & Samples $(n)$ \\
\hline 0 & None & Totally incorrect handling & No duplicate & Not reported \\
\hline 1 & Unpublished, but method described & No documentation & Duplicate portions & $1-2$ \\
\hline 2 & Modified from a published method & $\begin{array}{l}\text { Reasonable, documented, } \\
\text { common technique }\end{array}$ & Duplicate portions & $3-9$ \\
\hline 3 & Complete documentation published & $\begin{array}{l}\text { Extensively documented } \\
\text { and appropriate method }\end{array}$ & $\begin{array}{l}\text { Standards, reference materials, } \\
\text { spikes, recoveries or } \\
\text { blind duplicates }\end{array}$ & $\geq 10$ \\
\hline
\end{tabular}

* Modified from Greenfield \& Southgate (1992) and Mangels \& Holden (1993).

Table 2. Description of confidence codes and validation of analytical data by confidence codes

\begin{tabular}{|c|c|c|c|c|}
\hline \multirow[b]{2}{*}{ Confidence code } & \multirow{2}{*}{$\begin{array}{l}\text { Sum of quality } \\
\text { indices (points) }\end{array}$} & \multirow{2}{*}{$\begin{array}{l}\text { Interpretation of the } \\
\text { confidence code }\end{array}$} & \multicolumn{2}{|c|}{$\begin{array}{l}\text { Proportion of confidence code class of } \\
\text { the analytic values }(\%)\end{array}$} \\
\hline & & & Phytosterol values & Cholesterol values \\
\hline$A$ & $>9$ & $\begin{array}{l}\text { The user can have good confidence } \\
\text { in the mean value. }\end{array}$ & 81 & 96 \\
\hline B & $4-8$ & $\begin{array}{l}\text { The user can have some confidence } \\
\text { in the mean value. However, some } \\
\text { questions have been raised about the } \\
\text { value or the way it is obtained. }\end{array}$ & 19 & 4 \\
\hline $\mathrm{C}$ & $0-3$ & $\begin{array}{l}\text { Serious questions have been raised about } \\
\text { this value. It should be considered only } \\
\text { as a best estimate of the level of the } \\
\text { nutrient in this food. }\end{array}$ & 0 & 0 \\
\hline
\end{tabular}


Table 3. Classification of food codes used in the FINDIET 1997 survey by data type*

\begin{tabular}{|c|c|c|c|c|}
\hline & \multicolumn{4}{|c|}{ Classification of the new values: proportions (\%) of the 1374 food codes used in intake calculations } \\
\hline & $\begin{array}{l}\text { Analysed value } \\
\text { imputed as such }\end{array}$ & $\begin{array}{l}\text { Imputed from similar product } \\
\text { or calculated or derived } \\
\text { from analysed value }\end{array}$ & $\begin{array}{l}\text { Derived from } \\
\text { calculation of recipe }\end{array}$ & $\begin{array}{c}\text { Non-relevant } \\
\text { values }\end{array}$ \\
\hline Plant sterols & 7 & 11 & 60 & 22 \\
\hline Cholesterol & 9 & 21 & 63 & 7 \\
\hline
\end{tabular}

${ }^{*}$ For details of procedures, see p. 672 and FINDIET Study Group (1998).

\section{Results}

The confidence codes for the new analytical values are presented in Table 2. Almost all analysed values belong to the category with the highest confidence code, category A. One-fifth of all values are directly analytical. The rest of the sterol values for food items were imputed from analysed values or calculated from the analysed values with a recipe database (Table 3 ).

Per capita consumption data led to estimates of PS intake of $407 \mathrm{mg} / \mathrm{d}$ with the new database and $375 \mathrm{mg} / \mathrm{d}$ with the old one, i.e. a $9 \%$ higher intake level with the new database. The new Chol intake was $364 \mathrm{mg} / \mathrm{d}$ compared with $450 \mathrm{mg} / \mathrm{d}$ when using the old database, i.e. a $19 \%$ lower intake with the new database.

In the national FINDIET 1997 survey (FINDIET Study Group, 1998), the mean intake of PS was $305 \mathrm{mg} / \mathrm{d}$ for men and $237 \mathrm{mg} / \mathrm{d}$ for women, according to the new PS database (Table 4). The density of PS in the diet (mg total PS/ $1000 \mathrm{~kJ}$ energy intake) for men was lower than for women $(32.3$ v. $34.9 \mathrm{mg} / 1000 \mathrm{~kJ}, P<0.001)$. Sitosterol, campesterol and the sum of stanols (sitostanol and campestanol), in this order, were the major PS fractions in the diet (Table 4).

Subjects with the lowest educational level had the lowest intakes of PS $(P<0 \cdot 01)$, and those with the highest educational level had the highest intakes of PS $(P<0 \cdot 01)$, as

Table 4. Total intake $(\mathrm{mg} / \mathrm{d})$ and density $(\mathrm{mg} / 1000 \mathrm{~kJ})$ of plant sterols and cholesterol in the diet of Finnish men and women†

\begin{tabular}{|c|c|c|c|c|c|c|}
\hline & $\begin{array}{l}\text { Men } \\
(\mathrm{mg} / \mathrm{d})\end{array}$ & $\begin{array}{l}\text { Women } \\
(\mathrm{mg} / \mathrm{d})\end{array}$ & $\begin{array}{c}\text { Statistical significance } \\
\text { of effect }\end{array}$ & $\begin{array}{c}\text { Men } \\
(\mathrm{mg} / 1000 \mathrm{~kJ})\end{array}$ & $\begin{array}{c}\text { Women } \\
(\mathrm{mg} / 1000 \mathrm{~kJ})\end{array}$ & $\begin{array}{c}\text { Statistical significance } \\
\text { of effect }\end{array}$ \\
\hline Cholesterol & 284 & 201 & *** & $29 \cdot 7$ & $29 \cdot 6$ & NS \\
\hline \multicolumn{7}{|l|}{ Plant sterols } \\
\hline Sitosterol & 175 & 140 & $\star * \star$ & $18 \cdot 6$ & $20 \cdot 7$ & $* \star \star$ \\
\hline Campesterol & 70 & 52 & 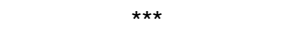 & $7 \cdot 3$ & $7 \cdot 5$ & $\star \star$ \\
\hline Stanols $\ddagger$ & 24 & 17 & 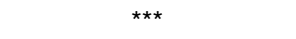 & $2 \cdot 6$ & 2.5 & NS \\
\hline Stigmasterol & 10 & 9 & 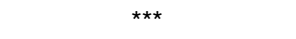 & $1 \cdot 1$ & $1 \cdot 3$ & 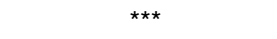 \\
\hline Avenasterol§ & 10 & 7 & $* \star *$ & 1.0 & $1 \cdot 1$ & ** \\
\hline Brassicasterol & 6 & 5 & $* \star \star$ & 0.7 & 0.7 & NS \\
\hline Other minor plant sterols\| & 10 & 9 & *** & $1 \cdot 1$ & $1 \cdot 3$ & $\star * *$ \\
\hline Total plant sterols & 305 & 237 & 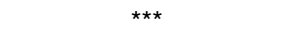 & $32 \cdot 3$ & 34.9 & $\star \star \star *$ \\
\hline
\end{tabular}

${ }^{\star \star} P<0.01,{ }^{\star \star *} P<0.001$.

$\dagger$ For details of procedures, see p. 672 and FINDIET Study Group (1998).

$\ddagger$ Sitostanol + campestanol.

$\S \Delta 5-+\Delta 7$-avenasterols.

\| Other desmethyl sterols (e.g. $\Delta 7$-stigmasterol, monomethyl sterols and dimethyl sterols).

Table 5. Intake of cholesterol and plant sterols by education and region†

\begin{tabular}{|c|c|c|c|c|c|c|}
\hline \multirow[b]{2}{*}{ Population group } & \multicolumn{3}{|c|}{ Plant sterols (mg/1000 kJ) } & \multicolumn{3}{|c|}{ Cholesterol (mg/1000 kJ) } \\
\hline & Men & Women & Total & Men & Women & Total \\
\hline \multicolumn{7}{|l|}{ Education } \\
\hline Low & $31 \cdot 1$ & $34 \cdot 0$ & $32 \cdot 7$ & $29 \cdot 1$ & $28 \cdot 8$ & $29 \cdot 0$ \\
\hline Middle & $32 \cdot 4$ & $35 \cdot 4$ & $34 \cdot 0$ & $29 \cdot 2$ & $29 \cdot 8$ & $29 \cdot 5$ \\
\hline High & $33 \cdot 3$ & $35 \cdot 3$ & $34 \cdot 4$ & $30 \cdot 8$ & $30 \cdot 3$ & $30 \cdot 6$ \\
\hline Statistical significance of effect & * & NS & * & NS & NS & NS \\
\hline \multicolumn{7}{|l|}{ Region } \\
\hline North Karelia & $33 \cdot 1$ & 35.4 & $34 \cdot 2$ & 28.6 & $29 \cdot 1$ & $28 \cdot 8$ \\
\hline Kuopio & $32 \cdot 6$ & $34 \cdot 6$ & $33 \cdot 7$ & $29 \cdot 0$ & $29 \cdot 8$ & $29 \cdot 4$ \\
\hline South-west (Turku-Loimaa) & $30 \cdot 9$ & $33 \cdot 6$ & $32 \cdot 4$ & $30 \cdot 4$ & $29 \cdot 7$ & $30 \cdot 0$ \\
\hline Capital (Helsinki) & $33 \cdot 0$ & $35 \cdot 8$ & 34.5 & $32 \cdot 0$ & $31 \cdot 8$ & $32 \cdot 0$ \\
\hline North (Oulu) & $31 \cdot 6$ & $35 \cdot 2$ & $33 \cdot 7$ & $28 \cdot 6$ & $27 \cdot 9$ & $28 \cdot 2$ \\
\hline Statistical significance of effect & ** & NS & * & NS & NS & * \\
\hline
\end{tabular}

${ }^{*} P<0.05,{ }^{* *} P<0.01$.

†For details of procedures, see p. 672 and FINDIET Study Group (1998). 


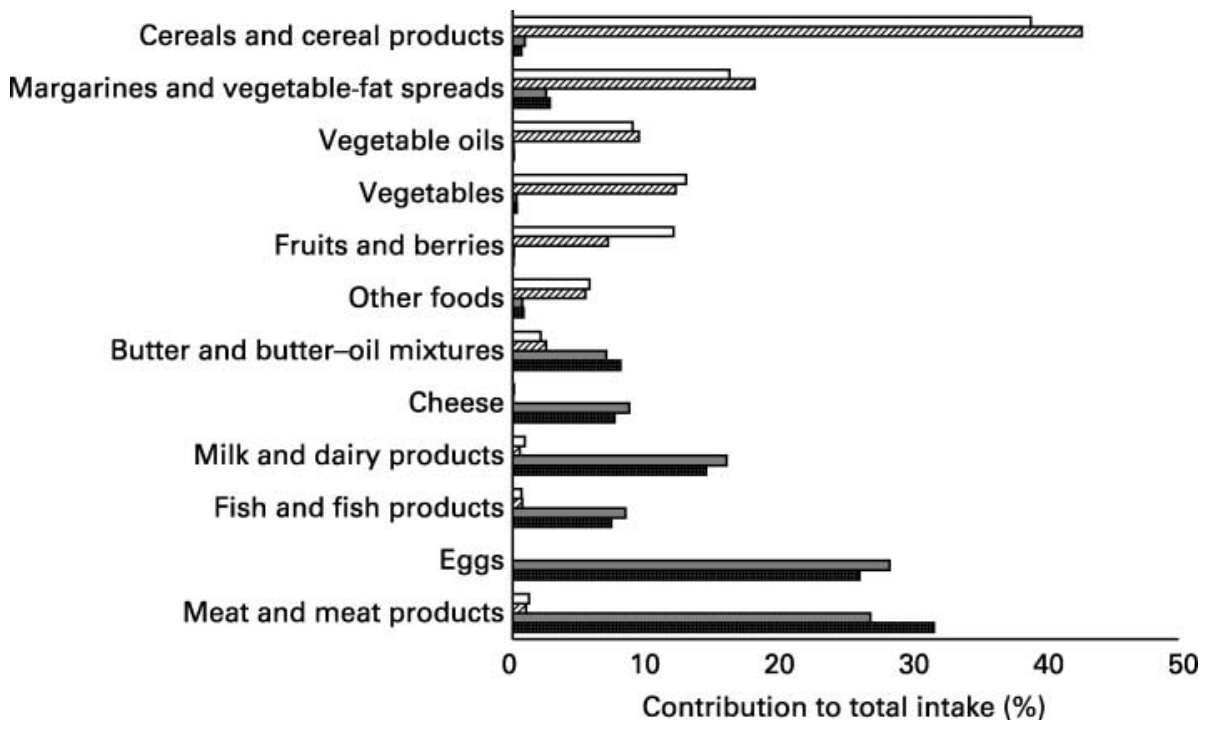

Fig. 1. Food groups as sources of plant sterols and cholesterol (\% total intake) in men and women in FINDIET 1997 Study (FINDIET Study

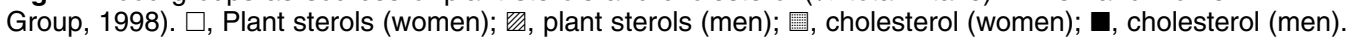

shown in Table 5. The PS density in the diet seemed to be highest in North Karelia $(P<0 \cdot 01)$ and lowest in southwestern Finland $(P<0 \cdot 01)$. No age-group differences were found in the density $(\mathrm{mg} / 1000 \mathrm{~kJ})$ of PS in the diet (results not shown). Cereal and cereal products, followed by margarine, were the main sources for PS (Fig. 1). Cereals, cereal products and especially rye contributed to the PS intake in the Finnish diet. Rye accounted for most of the intake of PS, on average $23 \%(24 \%$ in men and $19 \%$ in women); it was followed by other cereals, accounting on average for $19 \%$. The group of cereal products also included some baking fat, which increased the intake of PS from this group. Of dietary fats, margarines accounted for on average $17 \%$ (18\% in men and $16 \%$ in women) of PS intake, and vegetable oils for $9 \%$ among both genders. In addition, the group 'vegetables' was shown to be a good source of PS and accounted on average for $13 \%$ of the intake of PS (12\% in men and $13 \%$ in women).

The average intake of Chol was $284 \mathrm{mg} / \mathrm{d}$ for men and $201 \mathrm{mg} / \mathrm{d}$ for women. The Chol density $(\mathrm{mg} \mathrm{Chol} / 1000 \mathrm{~kJ}$ energy intake) of the diet did not differ between men and women (Table 4), nor was it affected by age (results not shown) or educational level (Table 5). Some regional differences in Chol intake were seen, however (Table 5). People in the capital area had a higher density of Chol in their diets than those in other areas of Finland $(P<0.05)$, and people in the north tended to have a lower density of Chol in their diets than those elsewhere in the country $(P<0.05)$. The main sources for Chol were meat, meat products and eggs (Fig. 1). Meat and meat products accounted for the intake of Chol, on average $29 \%$ (32\% in men and $27 \%$ in women), whereas eggs contributed on average $27 \%$ (26\% in men and $28 \%$ in women).

\section{Discussion}

When a new series of analytical values becomes available for a food composition database, quality evaluation of these values is essential. Various ranking systems have been developed for this purpose (Greenfield \& Southgate, 1992; Mangels \& Holden, 1993). The sampling procedure used for the PS analyses in the present study (Piironen et al. 2000b) is considered representative and covers the most important natural dietary sources of PS in Finland, identified by national food consumption data (FINDIET Study Group, 1998) and PS composition data of foods gathered earlier for other studies (Heinonen et al. 1997), but also using other sample planning techniques to evaluate the importance of the food sample to be analysed, e.g. Balance Sheets for Food Commodities 1998 and 1999 (Information Centre of the Ministry of Agriculture and Forestry, 2000). The quality of the analytical values was found to be high. Using imputed and recipe-calculated values for foods that had not been analysed and for mixed dishes ensured coverage of all food items.

In the present study, the PS and Chol values associated with the 1374 food codes used in the dietary survey were classified according to the origin of the data. Generally, the more analysed values there are in a database, the greater its reliability (Unwin, 2000). This classification confirmed 'the fitness for the purpose' (Greenfield \& Southgate, 1992) of the new analytical data, the purpose here being to calculate PS and Chol intake in a national dietary survey. An ideal approach would have been the reverse: first to identify the food codes used in the dietary survey and then chemically analyse the corresponding food items. However, such approach is not feasible practically, because of the very large number of food codes used.

The changes in PS intakes due to the revision of the database were estimated based on old and new values by comparing calculated intakes using food consumption figures from the Balance Sheets for Food Commodities 1998 and 1999 (Information Centre of the Ministry of Agriculture and Forestry, 2000). This comparison was supposed to reflect real shifts in the database, which originated in changes in analytical method, greater coverage of PS and Chol values in foods (fewer missing data) or real differences in food content. On the other hand, changes 
due to differences in values derived from changes in the recipe database (Hulshof et al. 1996) did not play a role in the per capita intake estimations.

The difference in PS intake calculated with the new database, relative to intake calculated with the old database, was $+9 \%$. Except for the breaking of glycosidic bonds in vegetable material before saponification by acid hydrolysis, no dramatic changes in analytical sample preparation methods for PS took place; it was expected, therefore, that the new intake estimates would be consistent with the old estimates, or perhaps somewhat higher. Higher estimates were predicted by the result of one recent study, in which acid hydrolysis was used and the PS concentrations obtained for wholewheat flour were $10 \%$ higher (Toivo et al. 2000). Thus, it appears that depending on the food matrix, at least for cereals, increases in analytical values can be as large as about $10 \%$. This factor alone could explain the difference between the estimates of PS in the Finnish diet obtained by per capita intake calculations with the two different food databases, since cereal and cereal products are a major source of intake.

Qualitatively the new values have two advantages over the old ones. First, almost all samples were Finnish, which makes it more likely that foods are analysed in the form in which they are actually consumed by the population. It should be noted, however, that this change may lead to lower or higher PS intake estimates, compared with the older values based mainly on data from foreign sources. Second, of a more technological interest for chemists, the analytical method used here identified and quantified several different PS that have not been reported on as extensively before. Traditionally, the stanols in food items (mainly sitostanol and campestanol) have been reported with their sterol counterparts. In the present study, the use of a capillary column allowed the separation of stanols, which are now reported separately. Since stanols very efficiently inhibit the absorption of not only Chol, but also of other PS, there might be good reason for reporting them separately (Gylling et al. 1999; Miettinen \& Gylling, 1999). In Finland, the consumption of whole grain is common, and rye products in particular contribute to the intake of stanols from the diet.

According to the comparisons based on the per capita consumption statistics (Information Centre of the Ministry of Agriculture and Forestry, 2000), the new Chol database generated a $19 \%$ lower intake estimate than the old one. The main reason for this difference could be the nonspecificity of the older colorimetric and enzymic methods (Scott Beyer \& Jensen, 1989; Fenton, 1992; Piironen et al. $2000 a$ ). It has been observed that these methods give higher values than specific chromatographic methods.

The intake of PS was estimated to have increased from 1987 to 1991 in the UK diet (Morton et al. 1995), due to increasing intake of vegetable oils. The same change in food consumption statistics has also been seen in Finland (Information Centre of the Ministry of Agriculture and Forestry, 2000). In addition to a greater intake of vegetable oils, the consumption of vegetables themselves has increased steeply and steadily since the 1960s in Finland (Information Centre of the Ministry of Agriculture and
Forestry, 2000). Consumption of cereals, on the other hand, has been declining somewhat over the decades. According to whole-diet samples representing diets in the 1960s (de Vries et al. 1997), men in eastern and western Finland consumed 218-232 mg PS/d during that decade. When we compare our present results with these values, it is obvious that the PS intake has increased in Finland. This increase can be interpreted as a reflection of the trend towards diets that are richer in vegetables and vegetable oils.

Earlier studies on differential food consumption and nutrient intakes (Roos et al. 1996; Valsta et al. 2000) concluded that women, and middle-aged and well-educated people, have intakes closest to the dietary recommendations. Their intakes of antioxidants, fibre and folate are relatively high, indicating greater consumption of vegetables. Even if the largest contribution to PS is from cereals, cereal products, vegetable oils and margarine, which are quite evenly distributed among men and women and by educational level, it is still the case that women and well-educated individuals obtain more PS per unit energy intake. For women, fruits and berries are also important sources of PS. The intake of cereal products, and especially rye, is a more important source of PS for men than for women.

The Chol density in the diet was found to be similar for men and women, even if the pattern of sources of Chol was different (Fig. 1). Meat, meat products and eggs are still the major sources of Chol for both genders. For women the intake of Chol from dairy products and especially cheese seems to be higher than for men, who in turn seem to obtain more Chol from butter than women do. This accords with known gender differences in major sources of saturated fats, which are also sources of Chol, in the Finnish diet (Roos et al. 1996).

Finally, we note that new eating habits in the population, variability of ingredients, changes in food preparation, substitutions for traditionally used cooking fats and introduction of new food items on the market are increasing the need for periodic database updates. However, even provided that there are regular revisions of values in food composition databases, there will always remain gaps in dietary intake estimates. The relative importance of, for example, cooking fat for PS and Chol intakes depends on the type of fat used (Hulshof et al. 1996; Perloff et al. 1998). PS content may vary from approximately 0 to $7000 \mathrm{mg} / \mathrm{kg}$, and Chol content from approximately 0 to $2000 \mathrm{mg} / \mathrm{kg}$, in different cooking fats. In dietary surveys, therefore, one important challenge remains when estimating PS or Chol intakes: missing information on the type of fat used in industrially produced food products.

In the present study, new PS and Chol databases covering food items that are regularly consumed by the Finnish population were successfully compiled and evaluated. The Chol content values for eggs and meat products in particular indicate the utility of occasional revisions of food composition databases, to account for changing analytical methods and especially for changes in food composition as well as food consumption habits. New intake estimates for PS and Chol obtained from the survey data indicate 
that the average PS:Chol ratio in our diet today is more beneficial, by exceeding $1 \cdot 0$, than it was some decades ago.

\section{Acknowledgements}

The authors would like to thank Heli Reinivuo for critially reviewing the manuscript and Christine Bartels for language editing of the paper. The work was supported by a grant from the Juho Vainio Foundation (Finland).

\section{References}

Anonymous (1997) Food, Nutrition and the Prevention of Cancer: A Global Perspective. Washington, DC: World Cancer Research Fund.

Awad AB \& Fink CA (2000) Phytosterols as anticancer dietary components: evidence and mechanism of action. J Nutr $\mathbf{1 3 0}$, $2127-2130$.

Carroll RJ, Ruppert D \& Stefanski LA (1995) Measurement Error in Nonlinear Models. Monographs on Statistics and Applied Probability 63. London: Chapman \& Hall.

De Vries J, Jansen A, Kromhout D, Bovenkamp P, Staveren W, Mensik R \& Katan M (1997) The fatty acid and sterol content of food composites of middle-aged men in seven countries. J Food Compost Anal 10, 115-141.

Fenton M (1992) Chromatographic separation of cholesterol in foods. J Chromatogr 30, 369-388.

FINDIET Study Group (1998) The 1997 Dietary Survey of Finnish Adults. B8/1998. Helsinki: Finnish National Public Health Institute.

Greenfield H \& Southgate DAT (1992) Food Composition Data. Production Management and Use, pp. 147-161. Great Yarmouth, Norfolk: Elsevier Science Publishers Ltd.

Gylling H, Puska P, Vartiainen E \& Miettinen TA (1999) Serum sterols during stanol ester feeding in a mildly hypercholesterolemic population. J Lipid Res 40, 593-600.

Heinonen M, Valsta L, Anttolainen M, Ovaskainen M-L, Hyvönen L \& Mutanen M (1997) Comparisons between analysed and calculated food composition data: carotenoids, retinoids, tocopherols, tocotrienols, fat, fatty acids and sterols. J Food Compost Anal 10, 3-13.

Hermann-Kunz E \& Thamm M (1999) Dietary recommendations and prevailing food and nutrient intakes in Germany. Br J Nutr 81, Suppl., S61-S69.

Hulshof K, Beemster C, Westenbrink S \& Löwik M (1996) Reduction in fat intake in the Netherlands: the influence of food composition data. Food Chem 57, 67-70.

Information Centre of the Ministry of Agriculture and Forestry (2000) Balance Sheet for Food Commodities 1998 and 1999 (preliminary). Helsinki: The Ministry of Agriculture and Forestry.

Kesäniemi YA, Ehnholm C \& Miettinen TA (1987) Intestinal cholesterol absorption efficiency in man is related to apoprotein E phenotype. $J$ Clin Invest 80, 578-581.

McNamara D (2000) Dietary cholesterol and atherosclerosis. Biochim Biophys Acta 1529, 310-320.

Mangels AR \& Holden JM (1993) Carotenoid content of fruits and vegetables: an evaluation of analytic data. J Am Diet Assoc 93, 284-296.

Miettinen T \& Gylling H (1999) Regulation of cholesterol metabolism by dietary plant sterols. Curr Opin Lipidol 10, 9-14.

Moghadasian M (1999) Effects of dietary phytosterols on cholesterol metabolism and atherosclerosis: clinical and experimental evidence. Am J Med 107, 588-594.
Moreau RA, Whitaker BD \& Hicks KB (2002) Phytosterols, phytostanols, and their conjugates in foods: structural diversity, quantitatative analysis, and health-promoting uses. Prog Lipid Res 41, 457-500.

Morton GM, Lee SM, Buss DH \& Lawrance P (1995) Intakes and major dietary sources of cholesterol and phytosterols in the British diet. J Hum Nutr Diet 8, 429-440.

Moschandreas J \& Kafatos A (1999) Food and nutrient intakes of Greek (Cretan) adults. Recent data for foodbased dietary guidelines in Greece. Br J Nutr 81, Suppl., S71-S76.

Nair PP, Turjman N, Kessie G, Calkins B, Goodman GT, Davidovitz H \& Nimmagadda G (1984) Diet, nutrition intake, and metabolism in populations at high and low risk for colon cancer. Dietary cholesterol, beta-sitosterol, and stigmasterol. Am J Clin Nutr 40, 927-930.

Normén L, Brants HAM, Voorrips LE, Andersson PA, van den Brandt PA \& Goldbohm RA (2001) Plant sterol intakes and colorectal cancer risk in the Netherlands Cohort Study on Diet and Cancer. Am J Clin Nutr 74, 141-148.

Normén L, Johnsson M, Andersson H, van Gameren Y \& Dutta P (1999) Plant sterols in vegetables commonly consumed in Sweden. Eur J Nutr 38, 84-89.

Ovaskainen M-L, Valsta L \& Luronen J (1996) The compilation of food analysis values as a database for dietary studies: the Finnish experience. Food Chem 57, 133-136.

Pelletier X, Belbraouet S, Mirabel D, Mordret F, Perrin JL, Pages X \& Derby G (1995) A diet moderately enriched in phytosterols lowers plasma cholesterol concentrations in normocholesterolemic humans. Ann Nutr Metab 39, 291-295.

Perloff B, Jaspreet K \& Ahuja C (1998) Development and maintenance of nutrient data bases for national dietary surveys. Public Health Rev 26, 43-47.

Piironen V, Lindsay D, Miettinen T, Toivo J \& Lampi A-M (2000a) Plant sterols: biosynthesis, biological function and their importance to human nutrition. J Sci Food Agric 80, 939-966.

Piironen V, Toivo J \& Lampi A-M (2000b) Natural sources of dietary plant sterols. J Food Compost Anal 13, 619-624.

Piironen V, Toivo J \& Lampi A-M (2002a) New data for cholesterol contents in meat, fish, milk, eggs and their products consumed in Finland. J Food Compost Anal 15, $705-713$.

Piironen V, Toivo J \& Lampi A-M (2002b) Plant sterols in cereals and cereal products. Cereal Chem 79, 148-154.

Piironen V, Toivo J, Puupponen-Pimiä R \& Lampi A-M (2003) Plant sterols in vegetables, fruits and berries. J Sci Food Agric 83, 330-337.

Roos E, Prättälä R, Lahelma E, Kleemola P \& Pietinen P (1996) Modern and healthy? Socioeconomic differences in the quality of diet. Eur J Clin Nutr 50, 753-760.

Salminen R (1997) Kasvisterolit sekä kolesteroli ravintorasvoissa (The cholesterol and plant sterol content of edible fats and oils). MSc Thesis, University of Helsinki.

Schothorst RC \& Jekel AA (1999) Oral sterol intake in the Netherlands: evaluation of the results obtained by GC analyses of duplicate 24-h diet samples collected in 1994. Food Chem 64, 561-566.

Scott Beyer R \& Jensen LS (1989) Overestimation of the cholesterol content of eggs. J Agric Food Chem 37, 917-920.

Tammi A, Ronnemaa T, Valsta L, Seppänen R, Rask-Nissila L, Miettinen TA, Gylling H, Viikari J, Anttolainen M \& Simell O (2001) Dietary plant sterols alter the serum plant sterol concentration but not the cholesterol precursor sterol 
concentrations in young children (the STRIP Study) Special Turku Coronary Risk Factor Intervention Project. J Nutr 131, $1942-1945$.

Toivo J, Lampi A-M, Aalto S \& Piironen V (2000) Factors affecting sample preparation in the gas chromatographic determination of plant sterols in whole wheat flour. Food Chem 68, 239-245.

Toivo J, Phillips K, Lampi A-M \& Piironen V (2001) Determination of sterols in foods: Recovery of free esterified and glycosidic sterols. J Food Compost Anal 14, 631-643.
Toivo J, Piironen V, Kalo P \& Varo P (1998) Gas chromatographic determination of major sterols in edible oils and fats using solid-phase extraction in sample preparation. Chromatography 48, 745-750.

Unwin I (2000) Eurofoods guidelines for recipe information management. J Food Compost Anal 13, 745-754.

Valsta L, Tapanainen H, Männistö S, Lahti-Koski M \& Pietinen P (2000) Differences in food consumption and nutritional quality of diet in Finland by gender, age and education. Scand J Nutr 44, Suppl. 37, S124. 